\title{
Lima Pertanyaan Tentang Sulawesi Selatan dan Lima Usulan Rencana Aksi: Berpegang Teguh pada Adat dalam Merajut Persatuan Kebangsaan
}

\author{
Ismail Suardi Wekke* \\ Pengurus Nasional Majelis Sinergi Kalam (MASIKA) \\ Ikatan Cendekiawan Muslim Se-Indonesia \\ Email: iswekke@gmail.com
}

Seminar Nasional

"Menuju Sulawesi Selatan Maju"

Majelis Sinergi Kalam Ikatan Cendekiawan Muslim Se-Indonesia

Pengurus Wilayah Sulawesi Selatan

Ruang Pola Kantor Gubernur Sulawesi Selatan, Makassar 26 Oktober 2019

\begin{abstract}
ABSTRAK
Sulawesi yang saat ini kita sebut Provinsi Sulawesi Selatan menjadi terasing dengan akarnya sendiri. Bahkan lebih takjub dengan budaya luar yang datang. Padahal, tidak seluruh bahasa di dunia ini memiliki aksara, diantara yang memiliki aksara itu, bahasa Bugis. Ini salah satu, dan modal utama dalam keunggulan komparatif di dunia. Makalah ini, menjadikan itu sebagai salah satu pertanyaan dari lima pertanyaan yang dikemukakan. Selanjutnya, juga mengemukakan lima usulan untuk menjadi rencana aksi Mewujudkan Sulawesi Selatan Maju.
\end{abstract}

Kata Kunci: Sulawesi Selatan; Bugis; Identitas

\section{Pendahuluan}

Sulawesi Selatan ketika itu masih Provinsi Sulawesi, dan dalam satu waktu bahkan pernah menjadi negara bagian Indonesia Timur. Juga dengan luas wilayah yang membentang sampai ke Mamuju dan Majene, kemudian saat ini menjadi Provinsi Sulawesi Barat. Dengan rentang kendali yang semakin pendek, dan juga kemampuan birokrasi dan juga masyarakat, maka ini momentum yang tepat untuk merefleksi kembali bagaimana Sulawesi Selatan untuk maju.

\section{Lima pertanyaan tentang Sulawesi Selatan}

1. Dimana homestay dengan Budaya Bugis atau 3 etnis Sulawesi Selatan tersedia?

Ada Balla Barakka di Takalar oleh Gurutta Prof. Aminuddin Salle. Akan sangat indah, kalau ada rumah yang bisa dijadikan sebagai hotel dengan seluruh ornament dan pernak-pernik etnik. Seperti rumah Bugis, termasuk dengan kehidupan orang Bugis di kampung. Silahkan gunakan mesin pencari di laman web, mengetikkan Rumah Bugis Bugis, justru tempat teratas itu akan memperlihatkkan Pontian, Benno, yang semuanya ada di Johor. Bukan di Sulawesi Selatan.

\footnotetext{
* Ismail Suardi Wekke, lahir di Camba, Sulawesi Selatan. Minatnya pada percakapan Bugis, dan kedaerahan membawanya menulis terkait Bugis. Diantara karya-karya itu
} 
Tempat-tempat untuk melestarikan tradisi dan semangat etnisitas perlu diperluas sehingga dapat diteruskan ke masa depan. Demikian pula kota dana kabupaten di Sulawesi Selatan, sudahkah menjadikan penciri arsitektur etnik menjadi bagian dalam mendirikan sebuah bangunan? Jangan sampai justru lebih menyerap ciri khas arsitektur Eropa atau Amerika dengan iklim yang sama sekali berbeda.

2. Bagaimana Bahasa Bugis? Bahkan disebutki pakkampong kalau Berbahasa daerah.

Menggunakan bahasa Bugis atau bahasa daerah di Makassar, akan langsung dicap kampungan. Padahal, berbahasa bukan soal kampong atau kota. Justru mendialogkan emosi dan perasaan. Akan sangat mudah kalau diskusi menggunakan bahasa pertama yang melibatkan emosi dan juga perasaan dimana bahasa lain tidak mampu mengungkapkan itu.

3. Dimana makan coto enak dan bersih dari Sisi Mata? Ada standar tertentu, bahwa makan coto itu enak kalau saat makan, kulit ketupat dibuang ke lantai.

Coto yang enak dalam percakapan distandarisasi dengan tungku dari periuk tanah, dibakar dengan kayu bukan gas, saat makan kulit ketupat cukup dilempar ke lantai. Bagi kita di Sulawesi Selatan, tak masalah. Kendala akan muncul kalau tamu-tamu datang dan kita perlu mengajak makan coto. Dimana tempat makan coto, konro, pallu basa yang standar higenisnya dapat digunakan wisatawan manca negara?

4. Tulisan tentang Bugis. Jangan sampai lebih eksis Bugis Malaysia dibanding Sulawesi Selatan.

Pada fase tertentu di Sulawesi Selatan, peneliti manca negara hilir-mudik untuk menuliskan tentang Bugis. Ada Pelras, Kathryn Robinson, dll. Hanya saja, fase itu sudah terlewati. Saatnya justru para cendekia kelahiran Sulawesi Selatan sendiri yang menuliskan dirinya. Kita perlu membaca tentang diri kita sendiri dari pandangan internal kita.

5. Apa program kolaborasi PT dengan pemerintah untuk memajukan Sulsel? Tidak ada prodi keBugis-an di perguruan tinggi Sulawesi Selatan.

Selain bahasa daerah, adakah sebuah program studi yang focus pada studi etnik atau kajian wilayah di Sulawesi Selatan. Prakarsa di Universitas Hasanuddin untuk membentuk guru bahasa daerah dengan perwakilan masing-masing kabupaten, itu langkah yang sangat bagus. Namun, saya khawatir kalau itu tidak berlanjut di era pemerintahan provinsi sekarang.

\section{Lima Usulan Rencana Aksi}

1. Kolaborasi riset daerah untuk penguatan identitas kesulawesian.

Badan Penelitian dan Pengembangan Daerah setiap tahun mengelola anggaran penelitian. Jika ini memungkinkan, maka perlu ada topik yang berhubungkait dengan Sulawesi Selatan dan Etnisitas. Begitu juga dengan setiap kabupaten dan juga kota, mengalokasikan penelitian dan pengembangan terkait dengan bahasa, dan budaya. 
Kajian ini perlu mempertimbangkan untuk sampai pada luaran penelitian berupa modul, atau bahkan yang lebih simpel yaitu naskah khutbah berbahasa Bugis, Makassar, Toraja, dan Mandar. Tidak saja di masjid, juga di gereja.

2. Sinergi pelaku wisata, kampus, dan Pemerintah Provinsi untuk homestay dengan berbasis pada tradisi etnik Sulawesi Selatan.

Paket-paket liburan ataupun paket belajar berorientasi pada kebudayaan Sulawesi Selatan. Ada pilihan daerah dan juga atraksi yang tidak tersedia di tempat lain. Jangankan di Indonesia, bahkan di seluruh dunia sekalipun. Hanya saja, ini tidak dieksplorasi sehingga pilihan konsumer tidak tersedia.

3. Kursus bahasa daerah. Termasuk mengintegrasikan bahasa dan budaya Sulawesi Selatan dalam aktivitas sekolah. Tidak mesti hadir dalam kurikulum untuk tidak membebani siswa lagi dengan tambahan mata pelajaran, tetapi kesempatan mengekspresikan bahasa dan budaya di lingkungan sekolah.

Mencari kursus bahasa Inggris bisa dimana saja. Mencari kursus bahasa Bugis? Entah ada dimana. Mahasiswa Indonesia di Kota Leiden bahkan menyediakan kursus bahasa Bugis. Tetapi itu temporer. Tidak semua bahasa di bumi ini memiliki aksara, diantara yang memiliki aksara itu adalah Bahasa Bugis, Makassar. Maka, tugas pemerintah provinsi bersama seluruh elemen masyarakat memastikan aksara ini masih digunakan.

4. Standarisasi kuliner etnis, di hotel, dan penyediaan pengiriman untuk konsumen global. Jamaah umroh, salah satunya terbesar dari warga Sulawesi Selatan, lalu adakah rumah makan di Saudi Arabia dengan menu Sulawesi Selatan?. Kalau bahan-bahannya diekspor ke Saudi, silahkan hitung pendapatan petani dan pedagang kita.

Kuliner Sulawesi Selatan bahkan sudah menjadi pilihan nasional seperti Mie Kering yang tersedia di Denpasar, Konro tersedia di Jakarta, dan Yogya. Begitu pula dengan Coto yang tersedia di Surabaya, Yogyakarta, dan Jakarta. Tidak itu saja, perlu intervensi pemerintah sehingga prakarsa masyarakat dapat tersedia di pelbagai tempat, bukan hanya karena inisiatif personal.

5. Program summer school \& degree tentang Sulawesi Selatan. Seperti Kars, Etnik, Pinisi, Bahari, dll.

Ada ragam alam dan budaya keanekaragaman hayati di bentangan wilayah Sulawesi Selatan yang hanya ada di provinsi ini. Kalau itu dikelola dengan pendekatan kurikulum, dan juga sinergitas dengan perguruan tinggi, langkah menjaga dan mengembangkannya akan lebih mudah.

Sebelumnya, pemerintah provinsi bersama Universitas Hasanuddin menyelenggarakan pendidikan dengan kekhususan bahasa daerah. Sepenuhnya, ini mendapat dukungan pendanaan 
dari pemerintah provinsi. Ini bisa menjadi salah satu program strategis yang diperluas ke perguruan tinggi sehingga dapat menjadi daya dukung dalam mempertahankan bahasa dan buadaya Sulawesi Selatan.

\section{Satu lagi, semuanya perlu ada flatform digital.}

Mencari informasi, sekarang cukup dengan mesin pencari di laman web. Maka, semua maklumat yang ada, perlu dikembangkan dengan flatform website. Termasuk pengembangan program yang berbasis aplikasi atau tersedia di laman web untuk keperluan penelusuran dan informasi awal bagi keperluan global.

\section{Dari Masa Lalu Untuk Masa Depan}

Buku Akhmar (2018) bisajadi buku terakhir yang terbit dengan topik Sulawesi Selatan. Ini bisa disimpulkan betapa tidak menariknya kajian Sulawesi Selatan. Sementara kita mengenal diri kita sendiri dari sarjana luar (Noorduyn, 1972; Pelras, 2000; Putra, 1988; Caldwell, \& Wellen, 2016; Millar, 1989; Ammarell, 1999; Acciaioli, 2000).

Sebelum Akhmar, terbit antara lain Rahman (2006) dan juga Rahman, \& Mariani, (2009). Mattulada (1975), Nurnaningsih (2015), Idrus (2004), Hamid (2004). Itu diantara tak lebih sepuluh cendekia yang menulis tentang kita dari pandangan internal. Kalangan cendekiawan muda seperti Yani (2007), Salim (2018) mulai menapak jenjang keilmuan. Hanya saja semuanya tumbuh dengan tanpa design bersama.

\section{Penutup}

Ini hanya letupan-letupan ide yang masih memerlukan eksplorasi lebih lanjut dengan tambahan data. Bisa jadi apa yang dikemukakan disini belum kontekstual dalam kondisi saat ini. Sebagai diskusi awal, maka perlu pengayaan lebih lanjut.

\section{Daftar Pustaka}

Acciaioli, G. (2000). Kinship and debt: the social organization of Bugis migration and fish marketing at Lake Lindu, Central Sulawesi. Bijdragen tot de taal-, Land-en Volkenkunde, 156(3), 589-617.

Akhmar, A. M. (2018). Islamisasi Bugis: Kajian Sastra Atas La Galigo Versi Bottinna I La Déwata Sibawa I Wé Attaweq. Jakarta: Yayasan Pustaka Obor Indonesia.

Ammarell, G. (1999). Bugis navigation. New Haven: Yale University Southeast Asia Studies.

Caldwell, I., \& Wellen, K. (2016). Family Matters: Bugis Genealogies and Their Contribution To Austronesian Studies. International Journal of Asia-Pacific Studies, 12.

Hamid, A. (2004). Pasompe: pengembaraan orang Bugis. Pustaka Refleksi.

Idrus, N. I. (2004). Behind the notion of siala: Marriage, adat and Islam among the Bugis in South Sulawesi. Intersections: Gender, History and Culture in the Asian Context, 10.

Mattulada. (1975). Latoa: satu lukisan analitis terhadap antropologi-politik orang Bugis:(a descriptive analysis of the political anthropology of the Buginese). Universitas Indonesia.

Millar, S. B. (1989). Bugis weddings: rituals of social location in modern Indonesia. Berkeley: Center for South and Southeast Asia Studies, University of California at Berkeley.

Noorduyn, J. (1972). Islamisasi Makassar (Vol. 15). Bhratara. 
Nurnaningsih, N. (2015). Pendidikan Kepribadian Dalam Pangadereng: Naskah Latoa Asimilasi dengan Nilai-nilai Islam. Lentera Pendidikan: Jurnal Ilmu Tarbiyah dan Keguruan, 18(1), 43-55.

Pelras, C. (2000). Patron-client ties among the Bugis and Makassarese of South Sulawesi. Bijdragen tot de Taal-, Land-en Volkenkunde, 156(3), 393-432.

Putra, H. S. A. (1988). Minawang: hubungan patron-klien di Sulawesi Selatan. Yogyakarta: Gadjah Mada University Press.

Rahman, N. (2006). Cinta, laut, dan kekuasaan dalam epos La Galigo: perspektif filologi dan semiotik. Makassar: La Galigo Press.

Rahman, N., \& Mariani, M. (2009). Kearifan lingkungan hidup manusia Bugis berdasarkan naskah Méong Mpaloé. Makassar: La Galigo Press.

Salim, A. (2018). Disputing Marriage Payments in Indonesia: A Comparative Study of Aceh and South Sulawesi. In Women and Property Rights in Indonesian Islamic Legal Contexts (pp. 127-145). Brill.

Yani, A. A. (2007). Budaya Politik Orang Bugis Dalam Dinamika Politik Lokal. Bugisnese Political Culture in Local Politics), Jurnal Masyarakat dan Budaya, Lembaga limu Pengetahuan Indonesia (LIPI), 9(2), 7. 